\title{
Covid-19: GPs call for same personal protective equipment as hospital doctors
}

\author{
Abi Rimmer
}

The BMJ

GPs have called for practices to be given the appropriate personal protective equipment (PPE) to protect themselves and staff from covid-19.

Speaking to The BMJ, Fay Wilson, medical director of the Badger out-of-hours cooperative, which covers Birmingham and Solihull, said that practices had received PPE but that it was not protective enough. She said that GPs should be receiving the same FFP3 respirator masks that were being issued to hospital staff.

"I would like to see a campaign for real PPE in general practice," said Wilson. "We've been given what I call 'cosmetic PPE,' which is the pinny, the gloves, and the little surgical mask-like you get in a doctors and nurses kit for the under $5 \mathrm{~s}$. Whereas the hospitals have got the proper thing.

"If we want there to be healthcare workers next week, and next month, we need to protect them now and not wait."

John Hughes, a Manchester GP, said on Twitter, "So GPs have finally been provided with PPE for [covid-19]. However, the supplies are not quite what is recommended; paper mask, plastic apron and gloves (all medium size). Barely adequate for cleaning the toilets."

Current guidance from Public Health England for primary care advises GPs that, if they have to enter a room with a patient with suspected covid-19, they should "wear personal protective equipment in line with standard infection control precautions, such as gloves, apron and fluid resistant surgical mask (FRSM)."

Some general practices have also reported not yet receiving any PPE at all. Monika Blackwell, a GP in south Gloucestershire, told The BMJ that her practice had not received any PPE yet. "We think it's on its way, but we're not sure," she said.

Michelle Drage, chief executive of Londonwide Local Medical Committees, told The BMJ that most practices in London had not yet received PPE as far as she was aware.
Leona Houston, a GP in Grampian, told The BMJ that her practice of 5500 patients had received just 50 fluid resistant surgical masks. "We are being told more PPE will be coming but not the details of what or when," she said.

\section{Uninterrupted supply}

Commenting on the issue, Martin Marshall, chair of the Royal College of General Practitioners, said that most practices seemed to have received their equipment.

"However, there are concerns among some of our members about whether this will be adequate as the official guidance changes," he added. "We are in close contact with NHS England and Public Health England and their equivalents across the UK to ensure that they can factor this feedback into their preparedness plans."

A spokesperson for the Department of Health and Social Care said, "We maintain large stockpiles of a range of personal protective equipment, including face masks, and these are being released in a controlled manner to help ensure the uninterrupted supply to the NHS.

"In line with well established procedures, the NHS is managing a rise in demand for certain types of PPE across the NHS above normal levels. There is no need for local stockpiling."

bmj.com Views And Reviews-Helen Salisbury: Is general practice prepared for a pandemic? (BMJ 2020;368:m944, doi:10.1136/bmj.m944)

Hughes JG. Twitter. 10 Mar 2020. https://twitter.com/johnghughes3/status/ 1237439867136729090.

2 Public Health England. COVID-19: interim guidance for primary care. Updated 25 Feb 2020. https://www.gov.uk/government/publications/wn-cov-guidance-for-primary-care/wncov-interim-guidance-for-primary-care.

Published by the BMJ Publishing Group Limited. For permission to use (where not already granted under a licence) please go to http://group.bmj.com/group/rights-licensing/ permissions 